\title{
ADVERSE EVENTS FOLLOWING MEASLES-MUMPS-RUBELLA VACCINATION. A PROSPECTIVE OBSERVATIONAL STUDY
}

\author{
CAMELIA BUCȘA ${ }^{1}$, NOEMI BULIK ${ }^{2 *}$, ANDREEA FARCAȘ ${ }^{1}$, SANDRA MUREȘAN $^{3}$, IOAN $^{2}$ \\ MUREȘAN $^{4}$, OVIDIU ONIGA ${ }^{2}$ \\ 1 “Iuliu Hațieganu” University of Medicine and Pharmacy, Drug Information Research Center, 6 Luis Pasteur Street, Cluj- \\ Napoca, Romania \\ 2 "Iuliu Hațieganu” University of Medicine and Pharmacy, Pharmaceutical Chemistry Department, 41 Victor Babeș Street, \\ Cluj-Napoca, Romania \\ ${ }^{3}$ Sandra Muresan Medical Office, 32 Moților Street, Cluj-Napoca, Romania \\ ${ }^{4}$ Ioan Muresan Medical Office, 5 Grigore Alexandrescu Street, Cluj-Napoca, Romania
}

*corresponding author: bulik.noemi@umfcluj.ro

Manuscript received: April 2019

\begin{abstract}
Measles outbreaks are spreading in many European countries due to parents' refusal to vaccinate their children motivated by the fear of adverse reactions. The aim of this study was to assess the adverse events (AEs) after measles-mumps-rubella (MMR) vaccination in general practice (GP). Children administered MMR vaccine according to the national immunization schedule (at about 1 year old and at about 5 years old) in two GP offices during March 2016 - May 2017 were followed-up for 6 months. We collected the selected solicited symptoms and medically attended AEs (MAEs) within 4 days and 6 months after vaccination, respectively. A total of 216 children, 123 aged 8 - 17 months (Group 1) and 93 aged 4 - 7 years (Group 2) received 219 MMR vaccines. At least 1 injection site reaction was reported for 14.63\% children in Group 1 and for $17.20 \%$ children in Group 2. We recorded 195 MAEs in Group 1 and 46 in Group 2. 5 MAEs were/may have been related to vaccination; all resolved without sequelae. The study confirmed the known safety profile of the MMR vaccine.
\end{abstract}

\section{Rezumat}

Epidemia de rujeolă persistă în multe țări europene întrucât părinţii refuză vaccinarea copiilor de teama apariției reacțiilor adverse. Scopul acestui studiu a fost evaluarea evenimentelor adverse (EA) apărute în urma vaccinării cu vaccinul rujeolăoreion-rubeolă (ROR) în practica generală. EA au fost colectate pe o perioadă de 6 luni la copiii vaccinați conform schemei naționale de imunizare (la vârsta de 1 an și 5 ani) din 2 cabinete de medicină de familie în perioada martie 2016 - mai 2017. $\mathrm{Au}$ fost colectate EA așteptate pentru perioada de 4 zile după vaccinare și EA care au necesitat consult medical (EAM) în decurs de 6 luni după vaccinare. 216 copii, 123 cu vârsta 8 - 17 luni (Grupul 1) și 93 cu vârsta 4 - 7 ani (Grupul 2), au primit 219 doze de vaccin ROR. A fost raportat cel puțin un EA așteptat la 14,63\% din copii în Grupul 1 și la 17,20\% din copii în Grupul 2. Au fost raportate 196 de EAM in Grupul 1 și 46 în Grupul 2. 5 EAM au avut/ar fi putut avea o relație de cauzalitate cu vaccinarea; toate s-au rezolvat fără sechele. Studiul a confirmat profilul de siguranță deja cunoscut al vaccinului ROR.

Keywords: childhood vaccination, MMR vaccine, vaccine safety, adverse events following vaccination

\section{Introduction}

Measles outbreaks are spreading in many European countries due to suboptimal vaccination coverage. Romania is among the countries with the highest number of measles cases in Europe since the beginning of the outbreak in 2016 [5].

A routine 2-dose measles-mumps-rubella (MMR) vaccination schedule led to the elimination of all 3 diseases in 14 - 15 years in Finland [10]. For the elimination of measles, vaccination coverage for both the first and the second dose must be at least $95 \%$ at all subnational levels and in all communities [5]. The vaccination coverage in Romania was below $94 \%$ in 2017 for the $1^{\text {st }}$ dose and below $84 \%$ for the $2^{\text {nd }}$ dose [5]. This situation is of concern as it was shown that in the United States, even minor reductions in childhood MMR vaccination, driven by vaccination hesitancy, have substantial public health and economic consequences [12], and this is expected to be applicable worldwide.

The suboptimal vaccination coverage is mainly due to parents' refusal to vaccinate their children and in turn this was found to be owed to the concern of adverse reactions $[1,14]$. Parents' confidence in the MMR vaccination may be raised by more information provided by the healthcare professionals. Safety data of the MMR vaccine in Romanian population (not published so far) could help both the healthcare professionals and authorities in enhancing the public confidence in MMR vaccine.

The objective of the present study was to assess the solicited and medically attended adverse events (AEs) 
occurring after MMR vaccination in general practice (GP) in the 2 age groups where the vaccine was recommended in the national immunization program: 9 - 12 months and 5 old.

\section{Materials and Methods}

Study design and setting

Our prospective observational study included all children vaccinated with MMR in 2 GP offices from Cluj-Napoca, Romania during March 2016 - April 2017. The national immunization schedule was modified towards the end of our study to administer the $1^{\text {st }}$ dose of MMR at 9 months and the $2^{\text {nd }}$ dose at 12 months due to measles epidemic. The vaccines used for MMR immunization were M-M-RVAXPRO ${ }^{\circledR}$ (offered free of charge by the Romanian Health System) and PRIORIX $^{\circledR}$ (bought by parents if they have chosen to). These were administered intra-muscularly (IM) or subcutaneous (SC), alone or concomitantly with other vaccines.

\section{Data collection}

A pharmacovigilance trained pharmacist interviewed the parents regarding the demographic characteristics of the children prior to the MMR vaccination. In addition to sex and age, we collected information on the gestational age at birth, the Apgar score, birth weight and height from the medical charts. We also recorded the history of feeding (breastfeeding/formula, diversification and if any changes have been made in baby's diet within 1 week prior to vaccination for the children aged 8 - 17 months), the medical history of the children and history of AEs after previous vaccinations, the usage of medication within 1 month prior to vaccination in face-to-face interviews complemented with the medical charts.

We collected the solicited local symptoms (pain, redness, swelling) and systemic reactions (dry cough, urticaria and rhinitis when these were not associated with other signs of infections) that might have occurred during days 0 - 3 after vaccination via online questionnaire that was filled-in by one of the parents. Grade 3 local solicited AEs were defined as crying when the limb was moved for pain and $>30 \mathrm{~mm}$ in diameter for redness and swelling. If the parent did not complete the questionnaire by the $4^{\text {th }}$ day after vaccination, a phone call was made to remind him to complete the questionnaire with the symptoms occurring during the 4 days' timeframe.

All medically attended AEs (MAEs) and serious AEs (that resulted in hospitalizations) of the children during the 6 months post-MMR vaccination follow-up were recorded from the medical charts and via phone calls. The phone calls were made at the end of the $6^{\text {th }}$ month after vaccination. Usually the results of a specialist physician consultation are registered to the GP office in Romania, especially if the consultation is made within the national health insurance system. However, patients may attend private physicians and may update the GP only latter, and this was the reason for additional phone contact when the parents were asked to provide the diagnosis set by the physician.

We also recorded the anxiety during vaccination in children 4 - 7 years of age (WHO criteria of immunizationanxiety-related reactions: fainting, hyperventilation, vomiting and convulsions) during the vaccination visit [30].

\section{Data evaluation and statistical methods}

Children aged 8 - 17 months old were included in Group 1 and children aged $4-7$ years old were included in Group 2.

The MAEs relatedness to the MMR vaccine was evaluated using a simplified WHO algorithm [28] and was deemed as follows: probably related for AE known from literature/Summary of Product Characteristics (SmPC), with matching the onset time and no alternative causes identified; possibly related for known $\mathrm{AE}$, matching the onset time and possible alternative cause of same strength at the most; probably not related for $\mathrm{AE}$ that may be known, with matching onset time and possible alternative cause of higher strength; not related for $\mathrm{AE}$ that may be known but with no matching onset time and possible alternative cause of higher strength.

All data was analysed descriptively and expressed as total number, percentage of total vaccinated children (or of children from one group) or as mean.

The study was part of a larger prospective study that covered all vaccines administered to children [3] which was approved by the Ethics Committee of "Iuliu Hațieganu" University of Medicine and Pharmacy, Cluj-Napoca, Romania, and was conducted according to the principles of Good Clinical Practice and the Declaration of Helsinki. Informed consent was obtained from all individual participants (children's parents) included in the study.

\section{Results and Discussion}

A total of 216 children received the MMR vaccine and were included in the study, 123 aged $8-17$ months (Group 1) and 93 aged 4 - 7 years (Group 2). The 216 children received $219 \mathrm{MMR}$ vaccine doses alone (92 doses in Group 1 and 77 in Group 2) or together with other paediatric vaccines (34 doses in Group 1 and 16 doses in Group 2). Of these, 210 children were included into the follow-up cohort $(6$ children did not follow-up: 5 moved to another area and 1 did not respond to phone calls).

The national vaccination schedule from Romania included 2 MMR vaccine doses at the ages of 12 months and 5 years, respectively, before the year 2017. Due to the increasing number of measles cases in 2016, this schedule has changed in January 2017. Our study ended the enrolment in April 2017, and though we only had 3 children vaccinated at 9 and 
12 months in Group 1. Two other children < 12 months of age received the $1^{\text {st }}$ MMR vaccine dose and did not receive the additional $2^{\text {nd }}$ dose within the 6-months follow-up period. In case of an MMR vaccination before the 12 months of age, it is recommended to administer a $2^{\text {nd }}$ dose of the vaccine ideally during 3 months after the $1^{\text {st }}$ dose, but at the latest before 15 months of age [6,9]. There is controversial evidence in the literature with regards to the efficacy or immunogenicity of MMR vaccination before the age of 12 months; some studies found that MMR vaccine is not as effective before as it is after this age [2, 21, 22]. This is explained by the inhibition of seroconversion of the vaccine by the maternal antibodies [4, 17]. In the light of these results our 2 children might have a higher susceptibility of measles infection. However, He et al. found more recently that similar immunogenicity is induced after MMR vaccination between 9 and 12 months of age as compared to $>12$ months of age [8]. One of the 2 children had post-vaccination measles. The symptoms occurred 7 days after MMR vaccination and consisted of vomiting, cough, fever $\left(39.2^{\circ} \mathrm{C}\right.$ intra-rectal) and specific skin eruption. The case was medically attended and was assessed as probably related to vaccination. Following this episode, the parents refused the $2^{\text {nd }}$ dose of the MMR vaccine and also the hexavalent vaccine which was due in the follow-up period of 6 months.

216 doses of M-M-RVAXPRO ${ }^{\circledR}$ and 3 doses of PRIORIX ${ }^{\circledR}$ were administered. Of the total vaccine doses, 52 were administered sc and 167 were administered im.

The demographic characteristics of both groups are presented in Table I.

Table I

Composition and codification of metronidazole gel formulations

\begin{tabular}{|c|c|c|}
\hline Characteristic & Group $1(\mathrm{~N}=123)$ & Group $2(\mathbf{N}=93)$ \\
\hline${ }^{\mathrm{a}}$ Age (mean, months [range]) & $11.37[8-17]$ & $69.84[49-94]$ \\
\hline Sex $(F$, number, \%) & $68(55.28)$ & $56(60.21)$ \\
\hline Gestational age at birth (mean, weeks) & 39.13 & 39.28 \\
\hline APGAR score (mean) & 9.61 & 9.52 \\
\hline Birth weight/height $(\mathrm{g} / \mathrm{cm})$ & $3359.47 / 53.43$ & $3369.70 / 53.80$ \\
\hline${ }^{\mathrm{b}}$ Breastfeeding exclusive (number, $\%$ ) & $61(49.59)$ & - \\
\hline${ }^{\mathrm{b}}$ Age of food diversification (mean, months) & 5.77 & - \\
\hline Food intolerance (number, \%) & $8(6.50)$ & $6(6.45)$ \\
\hline Allergies (number, \%) & $3(2.44)$ & $12(12.90)$ \\
\hline Chronic diseases (number, \%) & $6(4.88)$ & $18(19.35)$ \\
\hline History of AEs after prior vaccinations (number, \%) & $36(29.27)$ & $14(15.05)$ \\
\hline
\end{tabular}

Group 1, children vaccinated with MMR at 12 months of age [range $8-17$ months]; Group 2, children vaccinated with MMR at $\sim 5$ years of age; $\mathrm{N}$, number of children in given group; a, age at 1st vaccination in case of the 3 children with 2 doses of MMR; $b$, recorded for Group 1 only

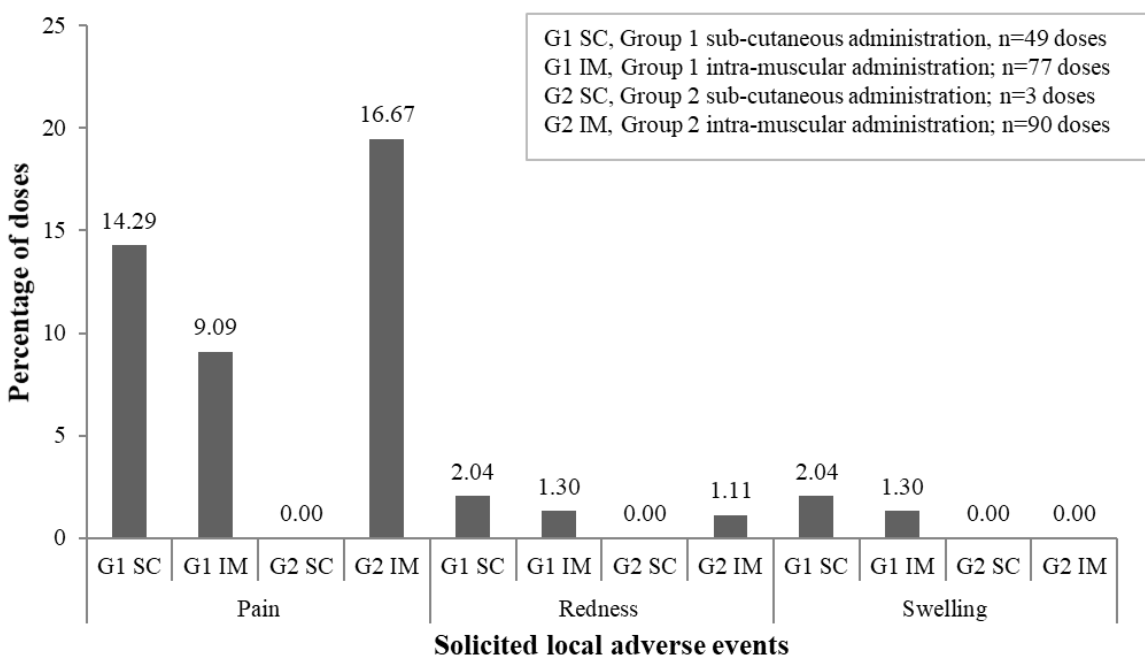

Figure 1.

Incidence of local solicited symptoms per dose of vaccine, during 4 days after vaccination, for children vaccinated with MMR

\section{Solicited adverse events}

The incidence of solicited local AEs per dose of vaccine is presented in Figure 1. The lowest incidence of any local symptoms was recorded in the Group 2, sc administration (0 symptoms) and the highest incidence in the Group $1 \mathrm{sc}(18.37 \%$ of doses). For the im 
administration, local symptoms were reported for $14.97 \%$ of the children $(11.69 \%$ and $17.78 \%$ of doses in the Group 1 and 2, respectively). At least 1 injection site reaction was reported for 18 children in Group 1 (14.63\%) and for 16 children (17.20\%) in Group 2. This is close to the results of the clinical trials where the median incidence of injection site reaction was $18.5 \%$ [range: $3.2 \%-34.3 \%$ ], and the SmPC of the M-M-RVAXPRO ${ }^{\circledR}(15.8 \%$ for the im administration as compared to our result of $15.57 \%$ for im administration), but lower than the WHO report $(17-30 \%)[10,16,29]$.

No grade 3 local solicited AEs were reported in any of the groups during the 4 days post-vaccination.

Among the solicited systemic AEs, rhinitis was the most frequent symptom (in 17 [7.87\%] children, 13 in Group 1 [4 when co-administered with other vaccines] and 4 in Group 2 [all when MMR was administered alone]), none in children with previously known allergies. Dry cough was reported in 13 children $(6.02 \%)$, of which 1 with known multiple allergies and 3 children in Group 2 with history of bronchitis or bronchi hyperreactivity. The incidence of cough and rhinitis was reported in the literature to be higher after MMR immunization $[6,18]$ and these are AEs listed in the SmPC of the MMR vaccines [16, 20]. Freeman et al. found that rhinitis and cough were reported by parents more often (in $20 \%$ of the children for rhinitis and $10-15 \%$ for cough) during the first week after immunization [6]. Similarly, a randomized, double-blind crossover study of MMR vaccine given to 581 pairs of twin siblings, found that cough and rhinitis occurred more often during the first week after immunization, in the MMR group than in children receiving placebo [18]. Urticaria was reported in 2 children in Group 2 (not medically attended) of whom one was accompanied by dry cough.

Medically attended adverse events

195 AEs needing medical attention were recorded during the 6 months after vaccination in Group 1 and 46 in Group 2. Table II lists the MAEs grouped as infections (total and per type), skin conditions, gastrointestinal conditions and others, according to the time of onset. The most frequent MAEs in both groups, for all evaluated periods were infections with different localization (unspecified aetiology). This doesn't mean though that there was a causal relationship between the vaccination and infections, as mostly because infections are the most common illnesses in children $<7$ years of age. On the contrary, several studies found no increased risk of infections after MMR vaccination, but a possible protective effect of the vaccine during the $1^{\text {st }}$ month after vaccination for both viral and bacterial infections [9, 15, 24]. The last affirmation should be regarded with caution though, as usually vaccinated children are in good health so these results could be due to healthy vaccine bias. One other study found that receiving MMR vaccine as the most recent vaccination is associated with a lower rate of admissions for upper and lower respiratory tract infections (URTI, LRTI) and gastrointestinal tract infections as compared to receiving the pentavalent vaccine [23].

URTI/LRTI were the most common type of infections in our study (approximately $13 \%$ of the children in Group 1 and $2 \%$ in Group 2, during the $1^{\text {st }}$ month after vaccination). These were reported in other studies to occur occasionally following vaccination with the MMR vaccine (less than $10 \%$ of the children) $[25,26]$.

Table II

Medically attended AEs of 211 children vaccinated with MMR and followed-up for 6 months

\begin{tabular}{|l|c|c|c|c|c|c|}
\hline & \multicolumn{3}{|c|}{ Group 1 (N = 120) } & \multicolumn{3}{c|}{ Group 2 (N = 91) } \\
\hline & $0-30$ days & $31-90$ days & $91-180$ days & 0 - 30 days & $31-90$ days & $91-180$ days \\
\hline Infections (any) & 19 & 56 & 88 & 4 & 10 & 19 \\
URTI & 13 & 40 & 57 & 1 & 7 & 12 \\
LRTI & 3 & 7 & 16 & 1 & 3 & 3 \\
Other & 3 & 9 & 15 & 2 & 0 & 4 \\
\hline Skin conditions & 0 & 2 & 5 & 0 & 0 & 0 \\
Urticaria & 0 & 2 & 4 & 0 & 0 & 0 \\
Dermatitis & 0 & 0 & 1 & 0 & 0 & 0 \\
\hline GI conditions & 3 & 3 & 5 & 0 & 0 & 1 \\
Abdominal pain & 1 & 0 & 0 & 0 & 0 & 0 \\
Diarrhoea & 1 & 4 & 5 & 0 & 0 & 1 \\
Irritable bowel & 1 & 0 & 0 & 0 & 0 & 0 \\
\hline Fever & 1 & 2 & 0 & 0 & 0 & 0 \\
\hline Other & 1 & 3 & 6 & 2 & 2 & 2 \\
\hline Total & 24 & 67 & 104 & 6 & 12 & 22 \\
\hline
\end{tabular}

Group 1, children vaccinated with MMR at $\sim 12$ months of age [range $8-17$ months]; Group 2, children vaccinated with MMR at $\sim 5$ years of age; N, number of children in a given group; URTI, upper respiratory tract infections; LRTI, lower respiratory tract infections; Fever, body temperature $>38^{\circ} \mathrm{C}$ not associated with other signs of infection; GI, gastrointestinal; GI conditions comprise only the listed GI symptoms with no signs of infection; gastroenterocolitis is included in other infections.

The incidence of MAEs was lower in the $1^{\text {st }}$ month after vaccination in Group 1 (0.20 MAEs/children) as compared to the months 2 - 3 (0.28 MAEs/child/ month) and months 4 - 6 (0.29 MAEs/child/month). 
In the Group 2 the incidence of MAEs was similar between the 3 periods $(0.03-0.035 \mathrm{MAEs} / \mathrm{child} /$ month) and lower as compared to the Group 1.

Of all MAEs, 1 case of diarrhoea that occurred 7 days after vaccination, 1 case of abdominal pain (11 days after vaccination) and 1 case of irritable bowel symptoms (3 - 4 undigested stools/day, diffuse abdominal pain, irritability that occurred 13 days post-MMR + hexavalent vaccination, had no prior history of gait disturbances, and lasted for 3 days) were assessed as possibly related to vaccination. LeBaron et al. found diarrhoea among the symptoms significantly more frequently reported during the 2 weeks after MMR vaccination as compared to the 2 weeks before vaccination [11]. The same timeframe of GI symptoms occurrence was found in a 14-year follow-up of children administered the MMR vaccine (within 20 hours to 15 days of receiving the MMR vaccine), with all events but 1 occurring after the first dose [19].

Other MAEs reported during the 6 months follow-up were otitis (not known if infectious or not, 6 cases), dry cough (4 cases), rhinitis, hyperkinetic syndrome, seizure (not febrile), fainting, anaemia and lymphadenitis ( 1 case each). They were all assessed as not related to vaccination.

Serious adverse events

In their refusal to vaccinate, parents' concerns are usually linked to serious or long-term effects of the MMR vaccine. Of the total number of MAEs, 12 were serious AEs (in 11 children), and all led to hospitalization. These were 6 cases of gastroenterocolitis with onset between 31 and 155 days after vaccination, 4 cases of bronchiolitis with onset 15 - 120 days after vaccination, 1 asthma and 1 fainting at 120 days after vaccination. These cases were considered as not related to vaccination. No death was reported. Anxiety-related events may also have a high impact on parents. Anxiety during vaccination was reported for $15(16.13 \%)$ children from Group 2. All were cases of hyperventilation accompanied with tachycardia. A review of studies looking at the anxiety-related events found that although all affected individuals recovered rapidly, vaccination program disruption was noted in some instances, sometimes for up to one year [13]. In our study these events were of low intensity (no fainting cases). Nevertheless, 1 non-serious MAE (measles case) leaded to non-compliance to the vaccination program at least for the 6 months of follow-up.

The limitations of our study are mainly related to the small number of children and the local character of the study. Nevertheless, this study brings prospective data from a geographic region of Europe that has no other published MMR vaccine safety prospective data, given that the safety of the biological medicines is of utmost importance [7]. Low- and middle-income countries are encouraged by WHO to detect, investigate and respond to vaccine safety concerns [27]. Another limitation would be the bias recall of some AEs by the parents. We tried to limit this bias by checking the medical charts for AEs, but some AEs that were attended in the emergency unit might have been missed.

\section{Conclusions}

Incidences of both solicited and medically attended AEs were higher in 8 - 17 months age group (after the $1^{\text {st }}$ MMR vaccine dose), as expected. The study confirmed the known safety profile of the MMR vaccine as we did not identify any new concerns related to the MMR vaccination. We identified only 5 MAEs that were/may have been related to vaccination; all resolved without sequelae, resulting in a positive benefit/risk balance.

\section{Conflict of interest}

The authors declare no conflict of interest.

\section{References}

1. Barbacariu CL, Parents' refusal to vaccinate their children: An increasing social phenomenon which threatens public health. Procedia Soc Behav Sci., 2014; 149: 84-91.

2. Black FL, Berman LL, Libel M, Reichelt CA, De P. Pinheiro F, Travassos Da Rosa A, Figueira F, Gonzales $\mathrm{S}$, Inadequate immunity to measles in children vaccinated at an early age: effect of revaccination. Bull World Health Organ.2 1984; 62: 315-319.

3. Bulik NB, Bucșa C, Leucuța D, Farcaș A, Cristina A, Mureșan S, Mureșan I, Oniga O, Reactogenicity and medically attended adverse events following hexavalent vaccination: an observational prospective study. Farmacia, 2019; 67(6): 1018-1024.

4. Edwards KM, Maternal antibodies and infant immune responses to vaccines. Vaccine, 2014; 47: 6469-6472.

5. European Centre for Disease Prevention and Control. Monthly measles and rubella monitoring report August 2018, www.ecdc.europa.eu.

6. Freeman TR, Stewart MA, Turner L, Illness after measles-mumps-rubella vaccination. CMAJ, 1993; 149: 1669-1674.

7. Ginghină O, Burcea-Dragomiroiu GTA, Gălățeanu B, Hudiță A, Dragomir S, Drăgănescu D, Bălănescu A, Roșca CA, Giuglea C, Popa DE, Pantea-Stoian A, Negrei C, Long-term safety of biosimilar medicinal products - key for administration?. Farmacia, 2019; 67(1): 18-26.

8. He H, Chen E, Chen H, Wang Z, Li Q, Yan R, Guo J, Zhou Y, Pan J, Xie S, Similar immunogenicity of measles-mumps-rubella (MMR) vaccine administrated at 8 months versus 12 months age in children. Vaccine, 2014; 32: 4001-4005.

9. Hviid A, Wohlfahrt J, Stellfeld M, Melbye M, Childhood vaccination and nontargeted infectious disease hospitalization. JAMA, 2005; 294: 699-705.

10. Kuter BJ, Brown M, Wiedmann RT, Hartzel J, Musey L, Safety and Immunogenicity of M-M-RII (Combination Measles-Mumps-Rubella Vaccine) in Clinical Trials of Healthy Children Conducted Between 
1988 and 2009. Pediatr Infect Dis J., 2016; 35: 1011-1020.

11. LeBaron CW, Bi D, Sullivan BJ, Beck C, Gargiullo $\mathrm{P}$, Evaluation of potentially common adverse events associated with the first and second doses of measles-mumps-rubella vaccine. Pediatrics, 2006; 118: 1422-1430.

12. Lo NC, Hotez PJ, Public health and economic consequences of vaccine hesitancy for measles in the United States. JAMA Pediatr., 2017; 171: 887892.

13. Loharikar A, Suragh TA, MacDonald NE, Balakrishnan MR, Benes O, Lamprianou S, Hyde TB, McNeil MM, Anxiety-related adverse events following immunization (AEFI): A systematic review of published clusters of illness. Vaccine, 2018; 36: 299-305.

14. McHale P, Keenan A, Ghebrehewet S, Reasons for measles cases not being vaccinated with MMR: investigation into parents' and carers' views following a large measles outbreak. Epidemiol Infect., 2016; 144: 870-875.

15. Miller E, Andrews N, Waight P, Taylor B, Bacterial infections, immune overload, and MMR vaccine: measles, mumps, and rubella. Arch Dis Child., 2003; 88: 222-223.

16. M-M-RVAXPRO Summary of Product Charateristics, www.ema.europa.eu.

17. Niewiesk S, Maternal antibodies: Clinical significance, mechanism of interference with immune responses, and possible vaccination strategies. Front Immunol., 2014; (16)5: 1-15.

18. Peltola H, Heinonen OP, Frequency of true adverse reactions to measles-mumps-rubella vaccine. Lancet, 1986; 1: 939-942.

19. Peltola H, Patja A, Leinikke P, Valle M, Davidkin I, Paunio M, No evidence for measles, mumps, and rubella vaccine-associated inflammatory bowel disease or autism in a 14-year prospective study. Lancet, 1998; 351: 1327-1328.
20. Priorix Summary of Product Charateristics, www.ema.europa.eu.

21. Redd SC, King GE, Heath JL, Forghani B, Bellini WJ, Markowitz LE, Comparison of vaccination with measles-mumps-rubella vaccine at 9,12 , and 15 months of age. J Infect Dis., 2004; 189: S116-S122.

22. Singh R, John TJ, Cherian T, Raghupathy P, Immune response to measles, mumps \& rubella vaccine at 9 , 12 \& 15 months of age. Indian J Med Res., 1994; 100: 155-159.

23. Sørup S, Benn CS, Poulsen A, Krause TG, Aaby P, Ravn $\mathrm{H}$, Live vaccine against measles, mumps, and rubella and the risk of hospital admissions for nontargeted infections. JAMA, 2014; 311: 826-835.

24. Stowe J, Andrews N, Taylor B, Miller E, No evidence of an increase of bacterial and viral infections following Measles, Mumps and Rubella vaccine. Vaccine, 2009; 27: 1422-1425.

25. Usonis V, Bakasenas V, Chitour K, Clemens R, Comparative study of reactogenicity and immunogenicity of new and established measles, mumps and rubella vaccines in healthy children. Infection, 1998; 26: 222-226.

26. Usonis V, Bakasenas V, Kaufhold A, Chitour K, Clemens R, Reactogenicity and immunogenicity of a new live attenuated combined measles, mumps and rubella vaccine in healthy children. Pediatr Infect Dis J., 1999; 18: 42-48.

27. WHO Global vaccine safety blueprint. The landscape analysis 2012, http://apps.who.int.

28. WHO-UMC standardised case causality assessment, www.who.int.

29. World Health Organization. Information sheet observed rate of vaccine reactions measles, mumps and rubella vaccines Geneva: WHO, www.who.int.

30. World Health Organization. WHO Vaccine safety basics. E-learning course. Module III: Adverse events following immunization, http://vaccine-safety-training.org. 